University of Nebraska - Lincoln

DigitalCommons@University of Nebraska - Lincoln

To Improve the Academy

Professional and Organizational Development Network in Higher Education

1995

Improving Teaching Through Reflective Partnerships

Roy Killen

Follow this and additional works at: https://digitalcommons.unl.edu/podimproveacad

Part of the Higher Education Administration Commons

Killen, Roy, "Improving Teaching Through Reflective Partnerships" (1995). To Improve the Academy. 335. https://digitalcommons.unl.edu/podimproveacad/335

This Article is brought to you for free and open access by the Professional and Organizational Development Network in Higher Education at DigitalCommons@University of Nebraska - Lincoln. It has been accepted for inclusion in To Improve the Academy by an authorized administrator of DigitalCommons@University of Nebraska - Lincoln. 


\section{Improving Teaching Through Reflective Partnerships}

\section{Roy Killen}

University of Newcastle

The purpose of this paper is to explain how both experienced and inexperienced faculty can improve their teaching and their students' learning through a systematic process of reflecting on their day-to-day teaching by collaborating with a "reflective partner. 'The suggestions are based on the author's experiences as a teacher, teacher educator and faculty developer, and on the belief that good teachers are those who help students to learn and to achieve their full potential as individuals. The reflective teaching techniques in this paper have a strong focus on the technical aspects of teaching. However, the techniques also provide faculty with opportunities to reflect on broader issues such as the beliefs that guide their teaching practices. By following the suggestions in this paper, faculty can identify their teaching strengths and limitations, develop the confidence to experiment with new teaching strategies to overcome these limitations, and gain a better understanding of all aspects of their teaching.

\section{What is reflective teaching?}

Educational literature contains numerous references to the idea that teachers ought to be reflective about their teaching. Terms such as reflective teaching, reflection on teaching, reflection in action, critical reflection, and reflectivity are frequently used to label the concept of teacher reflection (e.g., Zeichner \& Liston, 1987; Ross, 1989; Martinez, 1990; Van Manen, 1991; Onosko, 1992). These terms all refer 
to the general notion of teachers thinking about their teaching, although different authors place different emphases on how that thought should be encouraged and directed, and what its focus and ultimate purpose should be. Most writing in this area seems to be based either directly or indirectly on the work of Dewey (1933), or on some of the better-known modern writers on the topic such as Van Manen (1977), Zeichner (1981-82, 1983, 1987), Schön (1987), and Cruickshank (1987). The suggestions that these writers make all have as their general aim "the development of teachers who have the skills and dispositions to continually inquire into their own teaching practice and into the contexts in which their teaching is embedded" (Zeichner, 1987, p.565).

The various viewpoints on reflection can be distinguished by the approaches that they take to four issues: the process of reflection, the content or focus of reflection, the preconditions of reflection, and the product of reflection. The variations can, in many cases, be traced to the different philosophical bases for the approaches. For example, the work of philosophers of practical action such as Gauthrie (1963) has been applied by curriculum theorists such as Van Manen (1977) to produce the notion that teaching should be viewed as a series of practical problems, requiring deliberation and action for their solution. In contrast, the work of writers such as Habermas (1974) has encouraged a critical science concept of reflection as a process for becoming aware of the influence of societal and ideological constraints on teaching practice, and of gaining control over those influences. From a practical viewpoint, reflection on teaching occurs when teachers take time to think about what they are doing, why they are doing it, and the consequences that their teaching has for students. Reflective teachers accept that their teaching practices, and the motives for those practices, should be questioned, and then actively pursue ways to improve their teaching.

Teachers can reflect in many different ways and at a number of different levels. For example, at a very basic level, they might think about what works in their classroom to maintain order; at another level, teachers might become concerned with the goals they are trying to achieve; at a more complex level, teachers might think about issues beyond the classroom, so that social issues such as equity and eman- 
cipation can inform the way they view their classroom practices. Zeichner and Liston (1987) suggest that teachers can employ several different kinds of criteria when reflecting. When using technical criteria, teachers concentrate on how they can apply their knowledge to achieve a given set of objectives. When using what Zeichner and Liston call educational criteria, teachers consider how the contexts in which they teach influence teaching and learning, and they consider the value of different educational goals. When using ethical criteria, teachers think about the moral and ethical aspects of teaching and education.

If teaching is taken for granted it becomes mechanical and ineffective. As teachers engage in thinking about their past actions, their current situation, and their future intentions, their teaching ceases to be routine and becomes reflective. By definition, reflective teachers think critically about all their teaching practices and accept that what happens in their classrooms should be questioned and, if necessary, changed. This does not mean that reflection is concerned just with teaching techniques. It does mean that all aspects of teaching, including the teacher's attitudes, beliefs, behaviors and perceptions should be open to review. Indeed, as Noffke and Brennan (1988) suggest, the real choice for teachers is not so much whether or not to be reflective, but rather what to reflect upon.

\section{Why should teachers reflect?}

The benefits of reflection are considerable and tangible. For example, Korthagen and Wubbles (1991) provide evidence that reflective teachers have better interpersonal relationships with students than other teachers, and that they experience a higher level of job satisfaction. They also suggest that reflective teachers have strong feelings of security and self-efficacy, can talk and write readily about their experiences, and are more likely than non-reflective teachers to allow their students to learn by investigating and structuring things for themselves. The literature suggests several other reasons why teachers should be encouraged to be reflective. Some of these reasons have a sociological basis (Zeichner, 1992), while others clearly attempt to link reflection with teacher effectiveness in a technical or behaviorist 
way, that is, they suggest that through reflection teachers can improve their teaching and their students' learning (Cruickshank, 1987; Troyer, 1988; Killen, 1991). Others relate teacher reflection to measurable student or classroom factors such as thoughtfulness (Onosko, 1992). Whatever the prime motive for reflection, it is likely that reflective teachers will devote more time and effort to critical review and analysis of their teaching, and of their students' learning, than will teachers who are not reflective (Walker, et al., 1992). As a result, they are likely to have greater interest in self-improvement, have a greater interest in data on their teaching behavior, have higher self-esteem, make greater efforts to encourage their students to be reflective and to think critically, and believe that they have more power to influence student learning significantly (Nolan \& Huber, 1989).

\section{How can faculty reflect?}

The literature contains many suggestions about ways in which teachers can be encouraged to reflect on teaching, learning, and education. These strategies include the use of portfolios (Cole, 1991; Seldin, 1991), inquiry-oriented supervision (Ruddick \& Sigsworth, 1985; Zeichner \& Liston, 1987), cross-cultural teaching experiences (Vall \& Tennison, 1992), metaphors (Marshall, 1990; Hoffman, 1994), reflectivity training (Troyer, 1988), journal writing (Walker, 1985; Holly, 1989), action research (Lind, 1984; Zeichner \& Liston, 1987), modified action research (Hanna, 1986; Gore \& Ziechner, 1991), ethnographic studies (Gitlin \& Teitlebaum, 1983), collaboration (Shapiro, 1991), case studies (Hill, 1986), microteaching (Winitzky \& Arends, 1991), and Reflective Teaching lessons (Cruickshank, 1987; Killen \& Killen, 1992). These techniques for reflection could be grouped into what Garman $(1984,1986)$ refers to as processes of "reflection on action" and "reflection through recollection". In order for a teacher to reflect on action, segments of their teaching must be recorded as "stable data" so that they can be analyzed and interpreted at a later time. This recording might be on audio or video tape, or it could be verbatim data recorded by an observer. For reflection through recollection, a teacher simply recalls significant events and records them in a journal, or other suitable format, for further consid- 
eration. The techniques have one thing in common - they all encourage teachers to think about their teaching experiences and the effects that their teaching is having on students.

\section{The Reflective Partnership Procedure}

It is possible for faculty to learn a lot about their teaching by reflecting on it independently. This reflection can be enhanced if an audio or video recording is made of some lessons, and if a journal of teaching experiences is kept. However, there is a limit to how much you can learn from self-analysis. The benefits of reflection can be greatly enhanced if the process involves a sharing of ideas with a colleague. This basic idea is not new, and there are many references in the literature to faculty dyads, faculty triads, and various forms of mentoring (e.g., Kurth, 1994; Harnish \& Wild, 1994). The reflective teaching procedure described here is intended as a cooperative effort between two faculty members (referred to as reflective partners), who are able to share their teaching experiences by observing each other teach and by discussing their interpretations of each other's actions and intentions. The approach is based on the author's research into ways of helping faculty to learn from their own teaching. The reflective partnership technique helps faculty to engage in both reflection through recollection (remembering and discussing what happens in their classroom) and reflection on action (reflection stimulated by an audio or video tape of their teaching). This reflection helps faculty in a number of ways: perhaps the most important outcome is that involvement in this form of reflection helps faculty to realize that all aspects of their teaching should be open to question and review.

The faculty who form reflective partnerships will need to feel comfortable discussing things that happen in their classrooms, so they will need to develop a mutual trust and respect that will allow them to discuss issues in greater detail than they might through casual conversations. The cooperation and sharing of ideas starts with the reflective partners agreeing to observe each other teach. During the initial observations, it is important that the partners do not attempt to judge each other; they should simply observe and become familiar with the classroom, students, and general teaching style of their partner, and 
establish a common frame of reference for their later discussions. When each of the faculty is familiar with the general teaching style and classroom environment of their partner, they then select lessons in which they will make more formal observations as part of the reflection process.

For the purpose of the following explanation, the teacher who presents the first lesson will be referred to as the presenter, the other teacher will be referred to as the observer. The procedure starts with the presenter independently planning his or her first lesson, making decisions about what teaching techniques and resources to use, how to deal with individual student differences, how to show students the relevance of what they are learning, and all the other usual planning decisions.

The presenter then teaches the lesson with the observer watching but not participating in the lesson. During the lesson, the observer should make notes of what he or she saw (e.g., what the presenter did, how the students reacted, what things seemed to help students to learn, what things seemed to hinder student learning, and so on) in order to facilitate the post-lesson discussions. If it is convenient, the lesson can be videotaped to further assist the faculty with their later reflections.

Reflection on the lesson will be more productive if, towards the end of the lesson, the presenter seeks comments from students on what they think they learned and how they felt about the lesson. In some instances (such as with small classes), this feedback can be obtained through an informal discussion about the lesson. With larger classes, it is often more useful to get more formal feedback by using a written evaluation form. This can be as simple as asking the students to write down what they thought were the most important things they learned in the lesson, or how much of the lesson they thought they understood. They could also be asked to make a list of the things that the teacher did that helped them to understand the lesson, and another list of things that the teacher did that confused them. There will be other occasions where students can be asked to rate various aspects of a lesson on a tightly structured rating form. Examples of two suitable questionnaires are given in Appendices A and B.

As soon as possible after the lesson, the reflective partners should meet to discuss the lesson and compare their views of what happened 
and why it happened. A logical start to this discussion is for the presenter to describe how he or she planned the lesson, including such things as how they decided exactly what to teach and how to teach it, what assumptions they made about students' prior knowledge and how those assumptions influenced their planning, what basic beliefs about teaching and learning influenced their decisions, how much time they spent planning the lesson, what they wanted students to achieve, how and when they planned to assess what students had learned, and anything else that they thought influenced their planning. The purpose of this discussion on planning is to focus each teacher's attention on how and why they decide what to do in their classrooms, and the effects that this planning has on their teaching. Appendix $\mathrm{C}$ provides a list of questions that reflective partners can use to prompt their reflection.

The next phase of the reflection focuses on the presentation of the lesson, on the students' reactions to it, and on how the presenter reacted to unpredictable events in the lesson. The purpose of this phase of the reflection is to encourage the presenter to think about questions such as: What happened? Why did it happen? What could I have done differently? How did the students react to the lesson? This is likely to be a difficult phase, particularly in the early stages of reflective partnering, because initially the faculty may feel uncomfortable about discussing what happened in their lessons. To reduce the stress, the presenter can start by describing the strategies they used, explaining what they did and how effective they thought it was. It is important here for the faculty to reflect on how they felt during the lesson (e.g., confident, enthusiastic, frustrated), and to discuss how they thought their students felt (e.g., confused, bored, interested). During this discussion, the observer can offer comments to their reflective partner, based on their observations of what the presenter did and how students reacted during the lesson. These comments should be descriptive, not judgmental. The purpose of the joint reflection is not to find fault with what the presenter did, it is to help each teacher consider, in depth, issues that they might otherwise overlook. For example, a teacher who says "I felt really good about today's lesson" might be prompted to think further by a reflective partner asking a question such as "Did everything in the lesson happen the way you had planned it?" or "What 
do you think made the difference between today's lesson and your lesson last Tuesday?" Neither of these questions has a judgmental focus, yet each can be a prompt for useful reflection. "The key to successful reflection is in guiding participants away from being defensive to taking ownership of what they can reasonable change" (Rallis, 1994, p.265).

If the lesson was videotaped (or audio taped), the faculty can refer to these tapes to remind them of important things that happened in the lesson, to reveal to them things about which they were not aware, and to help them analyze the effectiveness of the teaching strategies that were used. The discussion stimulated by the videotape can focus on specific things such as how the lesson was introduced, how a particular concept was explained, or how the students were organized for an activity. The videotape can also convey a general impression about the lesson; were the students enthusiastic, did the teacher appear confident, was the lesson well organized? Appendix D contains some questions that teachers can use individually, or with a partner, to stimulate reflection on videotaped lessons.

After they have discussed the lesson from the point of view of the presenter and the observer, the reflective partners should consider the students' perspective on the lesson. Often, lecturers and students have quite different perspectives on teaching and learning (Killen, 1994; Rallis, 1994), and the comments they make can help to identify aspects of the lessons that the students found satisfying and aspects that may have caused them some concern. Particular attention should be paid to any comments that the students make that suggest they were having difficulty learning.

After considering the views of the presenter, the observer and the students, the reflective partners should make a brief summary of the strengths and weaknesses of the lesson and set targets for improvement so that the presenter will have some specific goals for improvement in his or her next lesson. If the reflective partners identify some problem or difficulty that they cannot solve, it may be appropriate for them to seek help from another source. This might involve discussing a difficult problem with another teacher or with a faculty developer, or it might mean searching for guidance in books or journals in the library. It will be very helpful for the faculty to keep a journal or diary 
of information that summarizes the processes and outcomes of their efforts to improve their teaching. This record will provide a valuable source of information that the faculty can review in the future, and it will also provide strong evidence of their commitment to self-improvement.

Once the reflective partners agree that they have learned as much as they can from analyzing the lesson, they can then agree on a time for the next reflective lesson (when they will change roles and the observer will become the presenter). The reflective process is then repeated. When the reflective partners teach similar subjects they should try to observe each other teaching similar topics in those subjects. This will provide an extra dimension to their reflection because it will allow them to compare very specific aspect of their teaching as well as reflecting on general issues. It will be productive to continue the sharing of experiences and ideas for at least six lessons (three presented by each partner) over a period of two to four weeks. At that time, the partners may decide that it will be beneficial to change reflective partners.

When faculty first engage in this guided reflection, they should select lessons for which the content is very clearly defined, that is, lessons for which they have very clear objectives and for which the scope of content, and the required depth of treatment of that content, can be easily stated. This clarity is needed so that the faculty will be able to easily compare what they did in each lesson and why they did it. It is easy for faculty from the same subject area to help each other reflect on their teaching because they have a common understanding of the content that is being taught. However, the reflective partners should not restrict their reflections to discussions of content. They should focus on how and why the content was taught, what the students learned, how the lesson could be made more interesting, and so on. As the faculty get more skilled in describing and analyzing what happens in their classrooms, they will be able to reflect more easily on lessons for which the content or objectives may not be so clearly defined. They will also soon realize that their reflection needs to go beyond the technical aspects of teaching and that they need to consider broader issues such as the value of what they are teaching, the hidden messages 
they are conveying, and their explicit and implicit expectations of students.

As faculty become accustomed to reflecting on their teaching and sharing ideas about teaching with their colleagues, they can benefit from forming a reflective partnership with someone who teachers in a different subject area. This cross-subject cooperation adds several new dimensions to reflection. First, it makes it easier for the partners to focus their attention on the teaching strategies that are being used, rather than on the fine details of the content. Second, it may allow the observer to provide feedback from the perspective of a naive learner. Third, it reduces the stress on the presenter as they will not be worried about defending the particular interpretation that they are placing on the content. Finally, it exposes faculty to teaching approaches that they might never see in their own subject area.

\section{Conclusion}

Whatever techniques faculty use to stimulate and guide their reflection, they will become more aware of their strengths and limitations as a teacher. With this increased awareness, they will realize that many things they do help students to learn, and that some things they do are not very helpful. They will then be in a better position to plan to improve their teaching.

This paper has raised a number of issues about reflection, and provided some guidance for faculty who are willing to cooperate with a colleague in their quest to improve their teaching. If faculty reflect carefully on all aspects of their teaching they can: better understand what is happening in their classrooms; see how their teaching is influenced by factors such as their beliefs about teaching, social norms, traditions, and politics; view their lessons from the perspective of their students; question what they are teaching and why they are teaching it; question how they teach; improve relationships between faculty and their students; and, improve student learning. Of these reasons for reflecting, the last is clearly the most important. 


\section{References}

Cole, D. J. (1991). Developing reflection in educational course work via the professional portfolio. Gateways to Teacher Education, 4(1), 1-12.

Cruickshank, D. R. (1987). Reflective Teaching: The preparation of students of teaching. Reston, VA: Association of Teacher Educators.

Dewey, J. (1933). How we think. Boston: D. C. Heath.

Garman, N. B. (1984). Stable data and clinical supervision. A paper presented at the Annual Conference of the Association of Teacher Educators, New Orleans.

Garman, N. B. (1986). Reflection, the heart of clinical supervision: A modern rationale for professional practice. Journal of Curriculum and Supervision, 2(1), 1-24.

Gauthrie, D. P. (1963). Practical reasoning. Oxford: Oxford University Press.

Gitlin, A. \& Teitlebaum, K. (1983). Linking theory and practice: The use of ethnographic methodology by prospective teachers. Journal of Education for Teaching, $9(3)$, 225-234.

Gore, J. M. \& Zeichner, K. M. (1991). Action research and reflective teaching in preservice teacher education: A case study from the United States. Teaching and Teacher Education, 7(2), 119-136.

Habermas, J. (1974). Theory and practice. London: Heinemann.

Hanna, W. (1986). Improving student teacher effectiveness through action research projects. Action in Teacher Education, 8(3), 51-56.

Harnish, D. \& Wild, L.A. (1994). Mentoring strategies for faculty development. Studies in Higher Education, 19(2), 191-201.

Hill, S. (1986). Language education and field experiences. Journal of Teacher Education, $37(3), 56-59$.

Hoffman, D. (1994). Metaphors of teaching: Uncovering hidden instructional values. To Improve the Academy, 13, 109-120.

Killen, R. (1991). Modifying the clarity behaviours of experienced teachers through structured feedback. The South Pacific Journal of Teacher Education, 19(2), 103-115. Killen, R. (1994). Differences between students' and lecturers' perceptions of factors influencing students' academic success at university. Higher Education Research and Development, 13(2), 199-212.

Killen, R. \& Killen, A. (1992). Faculty development through reflective teaching. The Journal of Staff, Program, and Organizational Development, 10(2), 69-74.

Korthagen, F. A. \& Wubbles, T. (1991). Characteristics of reflective practitioners: Towards an operationalization of the concept of reflection. A paper presented at the Annual Meeting of the American Educational Research Association, Chicago.

Kurth, R. J. (1994). Using faculty peers to improve instruction in diversified college classrooms. Paper presented at the Annual Meeting of the American Educational Research Association, New Orleans.

Marshall, H. H. (1990). Metaphor as an instructional tool in encouraging student teacher reflection. Theory into Practice, 29(2), 128-132. 
Martinez, K. (1990). Critical reflections on critical reflection in teacher education. The Journal of Teaching Practice, 10(2), 20-28.

Noffke, S. E. \& Brennan, M. (1988). The dimensions of reflection: A conceptual and contextual analysis. A paper presented at the Annual Meeting of the American Educational Research Association, New Orleans, April.

Nolan, J. F. \& Huber, T. (1989). Nurturing the reflective practitioner through instructional supervision: A review of the literature. Journal of Curriculum and Supervision, 4(2), 126-145.

Onosko, J. J. (1992). Exploring the thinking of thoughtful teachers. Educational Leadership, 49(7), 40-43.

Rallis, H. (1994). Creating teaching and learning partnerships with students: Helping faculty listen to student voices. To Improve the Academy, 13, 255-268.

Ross, D. D. (1989). First steps in developing a reflective approach. Journal of Teacher Education, 40(2), 22-30.

Ruddick, J. \& Sigsworth, A. (1985). Partnership supervision. In D. Hopkins \& K. Reed (Eds.), Rethinking teacher education. London: Croom Helm.

Schön, D. A. (1987). Educating the reflective practitioner: Toward a design for teaching and learning in the professions. San Francisco: Josey-Bass.

Seldin, P. (1991). The teaching portfolio: A practical guide to improved performance and promotion/tenure decisions. Bolton, MA: Anker Publishing Company.

Shapiro, B. L. (1991). A collaborative approach to help novice science teachers reflect on changes in their construction of the role of science teacher. Alberta Journal of Educational Research, 37(2), 19-32.

Troyer, M. B. (1988). The effects of Reflective Teaching and a supplemental theoretical component on preservice teachers' reflectivity in analyzing classroom teaching situations. Unpublished doctoral dissertation, The Ohio State University, Columbus, Ohio.

Vall, N. G. \& Tennison, J. M. (1992). International student teaching: Stimulus for developing reflective teachers. Action in Teacher Education, 13(4), 31-36.

Van Manen, M. (1977). Linking ways of knowing with ways of being practical. Curriculum Inquiry, 6, 205-228.

Van Manen, M. (1991). Reflectivity and the pedagogical moment: The normativity of pedagogical thinking and acting. Journal of Curriculum Studies, 23(6), 507-536.

Walker, D. (1985). Writing and reflection. In D. Boud, R. Keogh \& D. Walker (Eds.), Reflection: Turning learning into experience. London: Kogan Page.

Walker, T. J., Adamsky, R. A., Brower, E. B. \& Hart, K. (1992). The reflective teacher: An outcome of program VITAL. Journal of Industrial Teacher Education, 29(2), 23-34.

Winitzky, N. \& Arends, R. (1991). Translating research into practice: The effects of various forms of training and clinical experience on preservice students' knowledge, skill, and reflectiveness. Journal of Teacher Education, 42(1), 52-65. 
Zeichner, K. M. (1981-82). Reflective teaching and field-based experience in teacher education. Interchange, 12(4), 1-22.

Zeichner, K. (1983). Alternative paradigms of teacher education. Journal of Teacher Education, 34(3), 3-9.

Zeichner, K. (1987). Preparing reflective teachers: An overview of instructional strategies which have been employed in preservice teacher education. International Journal of Educational Research, 11(5), 565-575.

Zeichner, K. (1992). Connecting genuine teacher development to the struggle for social justice. Issue Paper 92-1. East Lansing, MI: National Center for Research on Teacher Learning. ERIC Document ED344881.

Zeichner, K., \& Liston, D. (1987). Teaching student teachers to reflect. Harvard Educational Review, 57(1), 23-48. 


\section{APPENDIX A}

\section{A Simple Questionnaire for Obtaining Feedback from Stu- dents}

Students can be asked to answer these questions at the end of a lesson.

1. Please circle a number to indicate how much of this lesson you think you understood?
$0 \quad 1$
2
3
4
5
67
$\begin{array}{lll}8 & 9 & 10\end{array}$

Nothing

Everything

2. In this lesson what things did the teacher do to make it easy for you to understand the lesson content?

3. In this lesson what things did the teacher do that confused you or made it difficult for you to understand the lesson content? 


\section{Appendix B}

\section{Lesson Evaluation}

Please think about what the teacher did in this lesson and place ticks in the boxes to indicate how much you agree or disagree with each statement.

Agree strongly 5

Agree 4

Neither agree nor disagree 3

Disagree strongly

Disagree 2

\begin{tabular}{|l|l|l|l|l|l|}
\hline In this lesson the teacher ............ & 1 & 2 & 3 & 4 & 5 \\
\hline 1. Was we organized & & & & & \\
\hline 2. Was confident & & & & & \\
\hline 3. Was enthusiastic & & & & & \\
\hline 4. Appeared to know a lot about the subject & & & & & \\
\hline 5. Told students what the lesson objectives were & & & & & \\
\hline 6. Did not go too fast & & & & & \\
\hline 7. Did not go too slow & & & & & \\
\hline 8. Explained the meanings of words that I did not understand & & & & & \\
\hline 9. Made the information easy for me to understand & & & & & \\
\hline 10. Presented the lesson in steps that I could follow & & & & & \\
\hline 11. Spoke clearly & & & & & \\
\hline 12. Made it easy for me to see what was important in the lesson & & & & & \\
\hline 13. Made the lesson interesting & & & & & \\
\hline 14. Used suitable examples to explain main points & & & & & \\
\hline 15. Encouraged students to ask questions & & & & & \\
\hline 16. Gave satisfactory answers to students' questions & & & & & \\
\hline 17. Made me think for myself & & & & & \\
\hline 18. Encouraged students to be involved in the lesson & & & & & \\
\hline 19. Used the whiteboard or blackboard effectively & & & & & \\
\hline 20. Used the overhead projector effectively & & & & & \\
\hline 21. Gave me time to think about new information & & & & & \\
\hline 22. Asked questions to check students' understanding & & & & & \\
\hline 23. Gave a useful summary of the main points of the lesson & & & & & \\
\hline
\end{tabular}




\section{Appendix C}

\section{Questions that Reflective Partners Can Use to Stimulate Reflection}

When reflective partners are comparing their lessons, they can each other questions such as the following:

1. Did the lesson proceed in the way you had planned it? Why?

2. Did your students react to the lesson in the way you thought they would?

3. What specific things did you do to help the students understand difficult parts of the lesson?

4. Did you do anything that confused the students or made it difficult. for them to understand the lesson?

5. How did the students react to your lesson?

6. During the lesson, did you feel confident and enthusiastic? Why?

7. What did you do in the lesson to allow for individual differences in students' learning styles or abilities?

8. Do you think your students learned all that you wanted them to learn in this lesson? What brings you to that conclusion?

9. What did you do in the lesson to make students feel that they had some control over what they were learning?

10. What did you do to encourage the students to participate actively in the lesson?

11. Did anything in this lesson reinforce or contradict your beliefs about teaching or learning?

12. What did you learn about teaching from this lesson?

13. What did you learn about student learning from this lesson?

14. What are the positive features of this class?

15. What problems need to be addressed in this class?

16. What social norms were reinforced by your lesson?

17. What was there in your lesson that reflects the hidden curriculum?

18. What targets (for improvement) have you set yourself for this class, and are they realistic?

19. If you were to teach the lesson again tomorrow, what would you do differently? Why? 


\section{Appendix D}

\section{Questions to Assist in Self-analysis of Teaching}

The main reason for making an audio recording or videorecording of your lesson is to help you see how you appear to your students. By listening to the audiotape or viewing the videotape several times, you should be able to identify your major strengths as a teacher, and the aspects of your presentation that need to be improved. When reviewing your tape, ask yourself the following questions:

1. Did I appear to be interested in what I was teaching?

2. Did I appear to be enthusiastic about what I was teaching?

3. Did I appear to be well organized?

4. Did the students know what I wanted and them to learn and why?

5. Did I have any mannerisms that might annoy students?

6. Did I maintain eye contact with as many students as possible?

7. Were my verbal and non-verbal messages consistent?

8. Was my presentation fluent but well paced, with appropriate pauses and variations? Did I use inflections, volume, and emphasis to convey variations in meaning, or was my voice monotonous?

9. Did the students have to strain to hear me?

10. Was my voice friendly and pleasant?

11. What did I do to help the students understand the structure of the information I was presenting?

12. Did I vary my presentation to make it interesting?

13. Did I walk around unnecessarily or remain frozen in the one spot?

14. Could the students see clearly all the materials I used to visually support my presentation?

15. Was my teaching style authoritarian, democratic, or friendly? How did the students react to this style?

16. What sort of questions did the students ask me?

17. Which students participated most in the lesson? Why?

18. What can I do to improve the image that I project to my students? 